\title{
Extracellular Vesicle-Induced Differentiation of Neural Stem Progenitor Cells
}

\author{
Eleonora Stronati ${ }^{1,2}$, Roberta Conti ${ }^{1}$, Emanuele Cacci ${ }^{1}$, Silvia Cardarelli ${ }^{1}$, Stefano Biagioni ${ }^{1}$ (] \\ and Giancarlo Poiana ${ }^{1, *}$ \\ 1 Dipartimento di Biologia e Biotecnologie “Charles Darwin”, Sapienza Università di Roma, \\ Piazzale Aldo Moro 5, 00185 Roma, Italy \\ 2 Department of Biological Science, Southern Methodist University, Dallas, TX 75275, USA \\ * Correspondence: giancarlo.poiana@uniroma1.it; Tel.: +39-06-4991-2320
}

Received: 19 April 2019; Accepted: 25 July 2019; Published: 27 July 2019

\begin{abstract}
Neural stem progenitor cells (NSPCs) from E13.5 mouse embryos can be maintained in culture under proliferating conditions. Upon growth-factor removal, they may differentiate toward either neuronal or glial phenotypes or both. Exosomes are small extracellular vesicles that are part of the cell secretome; they may contain and deliver both proteins and genetic material and thus play a role in cell-cell communication, guide axonal growth, modulate synaptic activity and regulate peripheral nerve regeneration. In this work, we were interested in determining whether NSPCs and their progeny can produce and secrete extracellular vesicles (EVs) and if their content can affect cell differentiation. Our results indicate that cultured NSPCs produce and secrete EVs both under proliferating conditions and after differentiation. Treatment of proliferating NSPCs with EVs derived from differentiated NSPCs triggers cell differentiation in a dose-dependent manner, as demonstrated by glial- and neuronal-marker expression.
\end{abstract}

Keywords: extracellular vesicles; exosomes; neural stem progenitor cells; astrocytes; basic FGF; EGF

\section{Introduction}

During neural development, neural stem progenitor cells (NSPC) with a radial glia identity produce neurons and glial cells in a spatiotemporally regulated manner. This complex process is driven by both extrinsic and intrinsic signals that eventually determine the type and number of adult neural cells $[1,2]$. Despite major progress in this field, the molecular mechanisms as well as the extrinsic and intrinsic factors underlying lineage commitment in NSPCs remain only partially understood [3-5]. Cells displaying properties of neural stem progenitor cells have been isolated from different regions of embryonic and adult murine central nervous systems and cultured in vitro in the presence of growth factors that maintain NSPCs in a proliferative and undifferentiated state [6,7]; these cells retain some radial glia characteristics and upon growth-factor deprivation, NSPCs can undergo differentiation and give rise to a mixed population of neurons and glial cells [8].

The proper development and functionality of the nervous system relies both on the regulation of intrinsic gene expression and on the intercellular communication among neural cells, which may occur through different mechanisms, one of them being the release of different classes of vesicles into extracellular space. Extracellular vesicles are spheroidal particles with different sizes, biogenesis and release mechanisms; among them are exosomes, small vesicles (50-100 $\mathrm{nm}$ in diameter) generated by exocytosis of endosomal organelles, multivesicular bodies, secreted by many cell types and characterized by specific contents of lipids, proteins and nucleic acids strictly related to the cells of origin $[9,10]$. Some of the membrane proteins and lipids found in exosomes are unique to these vesicles and are commonly used as exosomal markers [11]. Comprehensive reviews of the role played by 
exosomes in a normal healthy nervous system, both during development and in adults have recently been published [12-14]. It is now widely accepted that exosomes represent an important vehicle of intercellular communication that allows parental cells to modify gene and protein expression in recipient cells $[10,13,15]$. Extracellular vesicles may contribute to cell-cell communication during embryonic development $[16,17]$. Several studies investigated exosome release from neuronal and glial cells $[12,14,18]$ and many efforts have been done to clarify their role in physiological and pathological states $[12,19]$. It has recently been reported that exosomes derived from mesenchymal stem cells promote neurogenesis and neurite remodeling [18]. The role that extracellular vesicles may play in the mechanism of communication among stem cells has been pointed out in a recent review, "Exchange of genetic information utilizing persistent bidirectional communication mediated by stem cell EVs could regulate stemness, self-renewal and differentiation in stem cells and their subpopulations" [11]. Regulation of neurogenesis by extracellular vesicles in neurogenic niches has also been suggested [20-22].

The aim of our study is to determine whether neural progenitors and their progeny produce and secrete EVs and if the latter play a role in the differentiation of neighboring target cells.

\section{Results}

\subsection{Neural Stem Progenitor Cells Produce and Secrete EVs}

To determine whether NSPCs actively produce and secrete EVs, we cultured NSPCs obtained from 13.5-day-old mouse embryos (see Section 4) in Expansion Medium containing both Epidermal Growth Factor (EGF) and basic Fibroblast Growth Factor (bFGF). In these conditions, 85\%-90\% of cells are immunopositive to an anti-nestin antibody, indicating that they maintain an undifferentiated phenotype.

We analyzed the culture medium of the proliferating NSPCs and we determined the protein content of the EV fraction obtained as described in Materials and Methods: EVs are actively produced and secreted by proliferating cells and their rate of secretion reaches a maximum between 36 and $48 \mathrm{~h}$ in culture when cell confluence is at $60 \%-70 \%$ (Figure 1A).

A

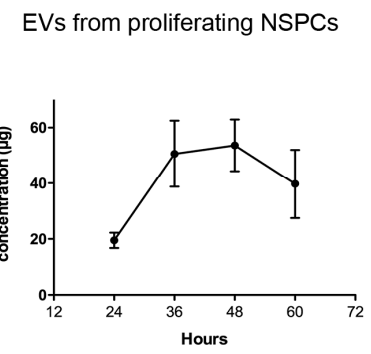

B

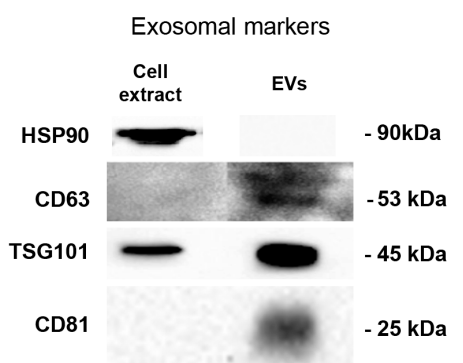

Figure 1. Extracellular vesicle (EV) secretion rate by proliferating neural stem progenitor cells (NSPCs) and analysis with exosomal markers. (A) Protein concentration measured in the EV fraction of culture medium of proliferating NSPC. Values are the mean of three independent experiments. (B) Western blots of exosomal markers in extracts of proliferating cells and of EVs secreted in $48 \mathrm{~h}$.

To ascertain whether the EV fraction from NSPCs cultured in Expansion Medium contained exosomes, we used exosomal markers such as HSP90, CD63, TSG101 and CD81 [23] and analyzed the EV fraction by western blot (Figure 1B), showing that it was enriched in some specific exosomal markers. We did not see any band for HSP90, probably because this specific marker is not present in extracellular vesicles produced by NSPCs. The blot for CD63 was overexposed in order to reveal the signal in the EV fraction.

Secretion was also assessed in NSPC cultures differentiated by using three different protocols. NSPCs were: (a) cultured in the presence of $10 \mathrm{ng} / \mathrm{mL}$ bFGF alone (bFGF differentiation medium), obtaining a mixed population of neurons and glial cells; (b) cultured in the presence of $5 \%$ Fetal Bovine 
Serum (FBS differentiation medium); (c) cultured in the presence of $20 \mathrm{ng} / \mathrm{mL}$ Bone Morphogenetic Protein 4 (BMP4 differentiation medium) [24]. In the last two culture conditions, enrichment in astroglial cells was achieved. We decided to also use BMP4 as a differentiating agent because, as specified in Section 2.2, its use may prevent the possibility that, even after FBS ultracentrifugation (see Section 4.2), exosomes still present in FBS may have influenced our results.

NSPCs, maintained in the presence of bFGF differentiation medium, differentiated into cells exhibiting an astrocytic and neuronal phenotype, as demonstrated by anti-Glial Fibrillary Acidic Protein (GFAP) and anti-Microtubule Associated Protein (MAP2) labelling. In particular, after three days in culture, $30 \%-35 \%$ cells were GFAP-positive, $15 \%-20 \%$ were positive for the neuronal marker MAP2 and the remaining cells were undifferentiated, as revealed by nestin labelling, in agreement with previous results from our laboratory [8]. When cells were cultured for three days in the presence of either FBS differentiation medium or BMP4 differentiation medium, labelling for GFAP was about $50 \%$ and $70 \%$ respectively, thus mainly inducing astrocytic differentiation.

We compared EV secretion in the medium of NSPCs in proliferating conditions (+EGF+bFGF) and in differentiated NSPCs using three methods to induce cell differentiation, i.e., $10 \mathrm{ng} / \mathrm{mL}$ bFGF (bFGF EVs), 5\% FBS (FBS EVs) or 20 ng/mL BMP4 (BMP4-EVs). Results are shown in Figure 2.

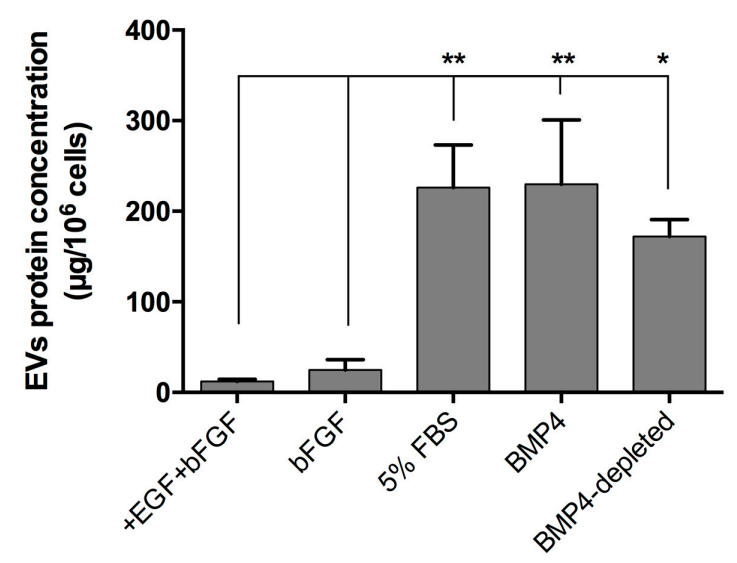

Figure 2. EV secretion by NSPCs maintained under different culture conditions for three days. Proliferating cells were cultured under proliferating conditions (+EGF+bFGF) and in differentiated conditions in the presence of bFGF or FBS or BMP4. Furthermore, cells were maintained for three days with BMP4 and then for two additional days in the absence of BMP4 (BMP4-depleted). Values are the mean of at least three independent experiments. Statistical analysis was performed by using an ANOVA test with multiple comparison. ${ }^{*} p<0.05 ;{ }^{* *} p<0.01$.

As shown, cells obtained by astrocytic differentiation released a much higher amount of EVs in extracellular space compared to proliferating cells or differentiated cells obtained omitting EGF. To exclude the effect due to the possible contamination of differentiating factors in the medium of EV collection, we determined the amount of EV released from NSPCs differentiated in the presence of BMP4 for three days and then maintained the cells for two more days in a basal medium. The EVs were collected from the medium of the last two days and referred to as BMP4-depleted EVs. We conclude that cells obtained in the two conditions of astrocytic differentiation released the same amount of EVs and that the amount of EVs was not significantly different, depleting the medium from differentiating agent BMP4 (BMP4 EVS versus BMP4-depleted EVs is not significant, with $\mathrm{P}=0.371$ ). Western blot analysis with exosomal markers showed no differences between EVs secreted by proliferating cells and by cells differentiated under the conditions described in Figure 2.

\subsection{FBS and BMP4 EVs Enhance Differentiation of Proliferating NSPCs}

NSPCs were maintained for three days in Expansion Medium (+bFGF+EGF) and daily supplemented with fresh EV preparations obtained from NSPCs differentiated with FBS differentiation 
medium. This preparation was called FBS EVs. We used two different concentrations of EVs (7.5 and $15 \mu \mathrm{g} / \mathrm{mL}$ ) to assess a dose-dependent effect on these cells due to the EVs. EV concentrations were chosen on the basis of previous observations described in the literature $[18,19,25]$. After three days of incubation, cells were stained with anti-GFAP, anti-MAP2 and anti-nestin antibodies (Figure 3).

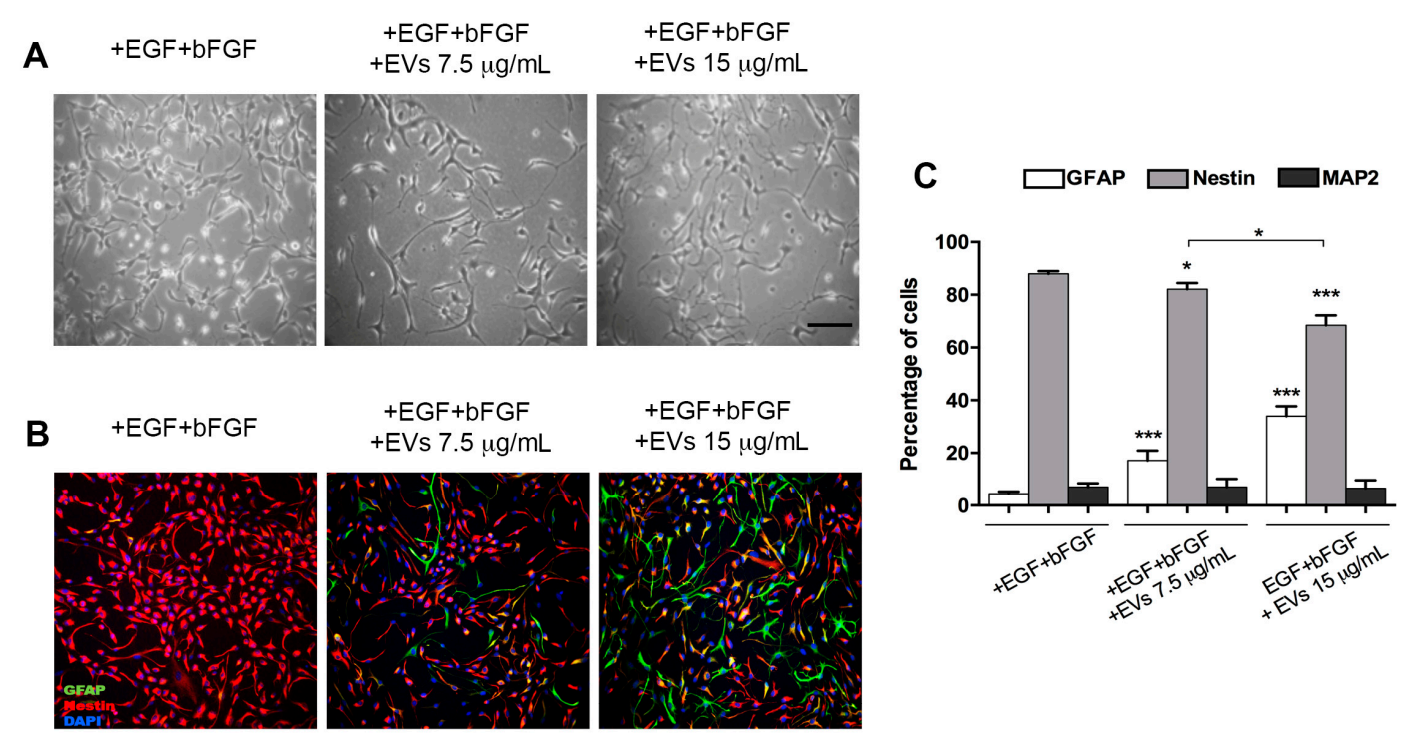

Figure 3. NSPCs maintained in medium containing +EGF+bFGF and treated or untreated with 5\% FBS EVs at 7.5 and $15 \mu \mathrm{g} / \mathrm{mL}$. (A) Bright-field images of cultures; (B) immunofluorescence labelling with anti-GFAP (green) and anti-nestin (red) antibodies and DAPI (blue); (C) quantification of GFAP-, nestinand MAP2-positive cells after three-day treatment with 5\% FBS EVs $(7.5$ and $15 \mu \mathrm{g} / \mathrm{mL})$ compared to untreated controls (+EGF+bFGF). Scale bar: $100 \mu \mathrm{m}$ (images in A and B have the same magnification). Values are mean of at least three independent experiments. ${ }^{*} p<0.05 ;{ }^{* *} p<0.0001$.

Astroglial-like morphology was developed by cells upon treatment with EVs but it was not exhibited by untreated cells. Percentage of immunostained cells for GFAP was increased, with GFAP-positive cells reaching $18.13 \% \pm 5.11 \%$ after EV treatment compared to nontreated NSPCs, with a parallel decrease of nestin expression. No changes in MAP2 staining were observed between treated and untreated NSPCs. Furthermore, we observed that differentiation could depend on EV concentration in the medium. In cells treated with double the concentration of EVs, we observed a higher increase of GFAP-positive cells $(34 \pm 3.75 \%)$ compared to nontreated cells $(4.47 \pm 0.82 \%)$, with a significant additional reduction of nestin-positive cells (from $87.97 \pm 0.64 \%$ to $68.48 \pm 3.47 \%$ ). In this case, differences in MAP2 staining were also not observed.

Although the centrifugation procedures described in the Materials and Methods section was adopted to avoid the presence of vesicles present in bovine serum [26], residual contamination of morphogenetic or differentiating agents was still possible, so we used the BMP4 differentiation medium to prepare EVs from astrocyte-enriched cultures [24].

Upon BMP4 treatment for three days, the number of cells expressing GFAP increased by up to $70 \%$, giving rise to a higher number of differentiated astrocytes that could produce a more homogeneous EVs population compared with that produced by FBS-differentiated cells.

The treatment of proliferating NSPCs with BMP4 EVs yielded several astrocytes significantly higher than the control cultures and the double concentration produced a significant increase of astrocytes with respect to both controls and to the lower EV concentration (Figure 4A-C). 

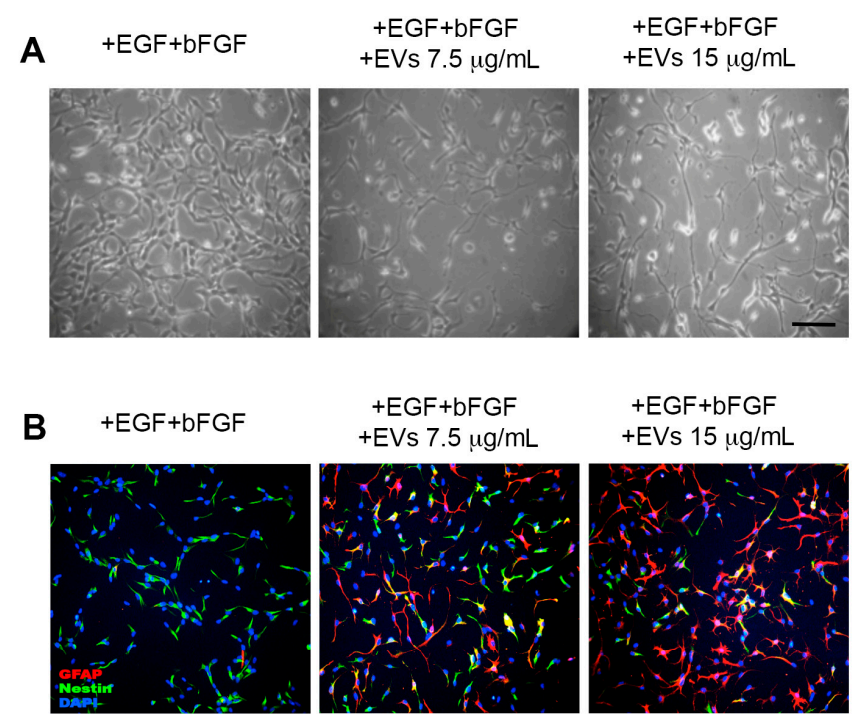

$+\mathrm{EGF}+\mathrm{bFGF}$ $+\mathrm{EVs} 7.5 \mu \mathrm{g} / \mathrm{mL}$

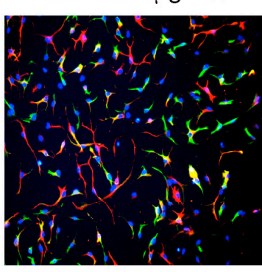

$+\mathrm{EGF}+\mathrm{bFGF}$ $+\mathrm{EVs} 15 \mu \mathrm{g} / \mathrm{mL}$

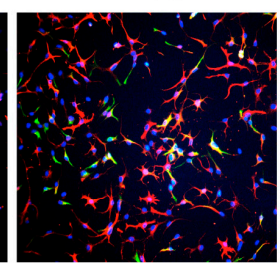

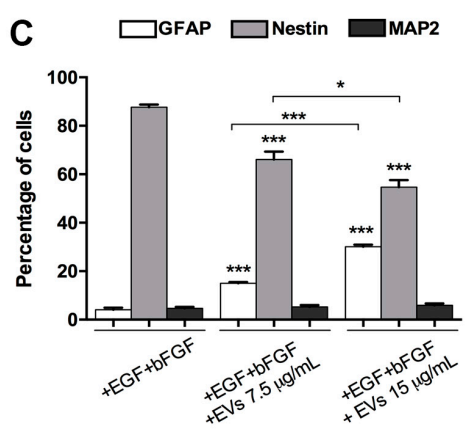

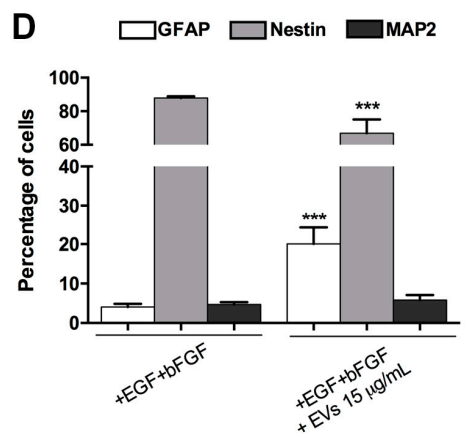

Figure 4. NSPCs maintained in a medium containing +EGF+bFGF, treated or untreated with BMP4 EVs at 7.5 and $15 \mu \mathrm{g} / \mathrm{mL}$. (A) Bright-field images of cultures; (B) immunofluorescence labelling with anti-GFAP (red) and anti-nestin (green) antibodies and DAPI (blue); (C) quantification of GFAP-, nestinand MAP2-positive cells, incubated for $72 \mathrm{~h}$ with BMP4 EVs $(7.5$ and $15 \mu \mathrm{g} / \mathrm{mL})$, obtained from cells treated for three days with BMP4, compared to untreated controls (+EGF+bFGF); (D) quantification of GFAP-, nestin- and MAP2-positive cells, incubated for $72 \mathrm{~h}$ with EVs $(15 \mu \mathrm{g} / \mathrm{mL})$ obtained from cells, first treated for three days with BMP4 and then for two additional days without BMP4 (BMP4-depleted), compared to untreated controls (+EGF+bFGF). Scale bar: $100 \mu \mathrm{m}$ (images in A and $\mathbf{B}$ have the same magnification). Values are the mean of at least three independent experiments. ${ }^{*} p<0.05 ;{ }^{* * *} p<0.0001$.

EVs collected during BMP4 treatment could themselves contain some BMP4 trapped during EV formation, which could itself in turn, induce a differentiating effect on EV-treated cells. Therefore, we treated NSPCs for three days with BMP4, then removed the medium containing BMP4 and collected and used the EVs secreted in the following $48 \mathrm{~h}$ in a BMP4-free medium (BMP4-depleted EVs). In this latter case, there was also significant increase in GFAP-positive cells $(20.04 \pm 4.21 \%)$ with respect to controls $(4.06 \pm 0.81 \%)$ and a decrease in nestin-positive undifferentiated cells (Figure $4 \mathrm{D}$ ).

In all experiments carried out with BMP4 EVs, MAP2-positive cells were always well below $10 \%$ of total cells and there was never any difference between the control and treated cells.

\section{Discussion}

In this paper, we showed that NSPCs from embryonic mouse spinal cords can release EVs among which exosomes are present, as demonstrated by the enrichment of well-known exosomal markers (TSG-101, tetraspanins CD63 and CD81) in our samples. The rate of secretion appears constant for about $48 \mathrm{~h}$, although exogenous factors, such as time in culture and cell-to-cell contact could have a significant impact.

Proof that NSPCs-derived EVs play a role in intercellular communication requires that these vesicles are taken up by NSPCs and that this event can modify the biology of target cells. It has been demonstrated that exosomes are uptaken in a selective way by neighboring cells and that their uptake can lead to the activation of cell proliferation and differentiation $[10,18,27]$.

We also demonstrated that EVs produced by differentiated neural progenitor cells can influence the phenotype of target cells; in particular, they can stimulate differentiation of proliferating NSPCs. 
In addition, we obtained EVs from cells that had been differentiated by two different methods: One pool of EVs was obtained from NSPCs differentiated with 5\% FBS (FBS EVs) and the other was produced by NSPCs cultured in the presence of BMP4 (BMP4 EVs); under both these culture conditions, NSPCs differentiated in a highly enriched astrocyte population. Proliferating NSPCs, treated with the EV pools produced in these two ways, showed an induction of differentiation toward an astrocytic lineage. Treatment with FBS EVs gave rise to approximately $40 \%$ astrocytes, while the remaining cells were still undifferentiated. Using BMP4 EVs, the yield in astrocytes was higher than controls, with a significant reduction of undifferentiated nestin-positive cells. We also showed that this induction was not dependent on the presence of morphogen BMP4 into the harvested EVs population by using EVs that were from NSPCs differentiated for three days with BMP4 and then maintained for two additional days in the absence of the differentiating agent (BMP4-depleted EVs), after which period EV harvesting took place.

In our experiments, EV treatment seemed to stimulate cells to differentiate, addressing target cells toward an astrocytic phenotype. In the literature, an opposite effect has recently been described, where exosomes produced by C6 glioma cells instead stimulated cell proliferation when incubated with primary cultures of rat cortical astrocytes [25]. The reason for such an opposite effect may reside in the cells of origin of the exosomes: It is likely that C6 glioma cells, being a tumor, may stimulate proliferation in order to increase the number of cells that invade the tissue. It is in fact well established that, together with some general markers that are common to all exosomes regardless of their source, many of the proteins and miRNAs transported by exosomes reflect the nature of their cells of origin.

The original result of this paper is that EVs produced and secreted by normal differentiated embryonic progenitor neural cells may activate the differentiation of normal NSPCs toward a specific phenotype, thus having a potential role in the process that takes place in the neural progenitor cell niche. The results shown in all previous papers reporting similar effects were obtained with exosomes produced either by tumor cells or by cell lines. Our data also suggest that EVs secreted by committed cells can induce or trigger the differentiation of proliferating cells. Furthermore, it is very interesting and worth further investigation that, when NSPCs were treated with EVs obtained from a mixed population of neuronal and glial cells, their differentiation always took place toward an astrocytic phenotype. EVs could contribute to the observed induction toward an astrocytic lineage, possibly by embedding miRNAs that were able to reprogram multiple cellular mechanisms in recipient cells.

Recently, it has been demonstrated that astrocytes and their exosomes share numerous miRNAs but some of them are uniquely expressed in exosomes [28]. It was also proven that vesicles released by cells could reflect the characteristics of their cells of origin (reviewed in [9]). These specific miRNAs present in exosomes probably control some differentiative targets in the recipient cells. In our model, it would be interesting to analyze the vesicular content of FBS or BMP4 EVs in order to clarify their role in the astrocytes' differentiation induction.

This study demonstrates that EVs from astrocyte-like cells can steer NSPC differentiation toward the glial lineage. We propose that, in addition to contact-dependent signals requiring cell-to-cell connection and the secretion of soluble factors such as cytokines and neurotransmitters from differentiated cells, communication through EVs can also provide the signals required for the activation of the gliogenic process, thereby contributing to the temporarily regulated transition from the neurogenic to the gliogenic phase during development. In the future, it is important to assess whether EV preparations from different neural cell types (e.g., neurons vs. astrocytes) can differently modulate NSPC properties and whether such mechanisms also occur in vivo.

\section{Materials and Methods}

\subsection{NSPC Cultures}

All animal-related procedures were carried out following the European Communities Council Directive No. 86/609/EEC (November 24, 1986). Animals were anesthetized and sacrificed by decapitation. 
NSPCs were obtained from E13.5 mouse embryonic spinal cord and adapted to cell cultures as previously described $[8,29,30]$. Cells were maintained in a medium referred to as the "Expansion Medium" consisting of basal medium (Dulbecco's Modified Eagle's Medium (DMEM)/F12, $1 \%$ penicillin/streptomycin, $0.1 \mathrm{M}$ L-glutamine (Sigma-Aldrich, St. Louis, MO, USA), $23.8 \mathrm{mg} / 100 \mathrm{~mL}$ Hepes, $7.5 \%$ NaHCO3, $0.6 \%$ glucose), supplemented with $20 \mathrm{ng} / \mathrm{mL}$ human recombinant EGF (EGF; R and D Systems, Minneapolis, MN, USA), $10 \mathrm{ng} / \mathrm{mL}$ of basic fibroblast growth factor (bFGF; Peprotec, London, UK) and $1 \% \mathrm{~N} 2$ supplement. NSPCs were routinely expanded in T25 flasks (Corning, Corning, NY, USA), coated with $10 \mu \mathrm{g} / \mathrm{mL}$ polyornithine and $5 \mu \mathrm{g} / \mathrm{mL}$ laminin (Sigma-Aldrich) and cultured at $37^{\circ} \mathrm{C}$ in a $5 \% \mathrm{CO} 2$ atmosphere. Cells were passaged every 3-5 days using Accutase (Sigma-Aldrich) and usually seeded at a density of $10,000-15,000$ cells $/ \mathrm{cm}^{2}$.

\subsection{Differentiation Conditions}

For astrocyte differentiation, NSPCs were plated in Expansion Medium $\left(6000 \mathrm{cells} / \mathrm{cm}^{2}\right.$ in T75-coated flasks) and $24 \mathrm{~h}$ later the medium was replaced with basal medium containing $1 \% \mathrm{~N} 2$, $2 \%$ B27 and $20 \mathrm{ng} / \mathrm{mL}$ BMP4 (Peprotech) or 5\% FBS (Sigma-Aldrich) and termed differentiating media. To eliminate the risk of adding EVs possibly present in bovine serum, FBS was routinely centrifuged overnight at 100,000 $\mathrm{g}$ before use [26].

After 3 days in the presence of BMP4, NSPCs differentiated into a highly enriched astrocyte culture (70\%-80\%); after 3 days of FBS, NSPCs differentiated into a mixed culture of glial cells (about $50 \%)$ and residual progenitor cells.

Mixed cultures of neurons and glial cells were obtained omitting EGF from the expansion medium, termed bFGF differentiation medium [31].

\subsection{Immunocytochemistry}

Cells were plated on glass coverslips coated with polyornithine/-laminin. At the appropriate time points, after fixation with $4 \%$ paraformaldehyde (PFA, Sigma-Aldrich) in PBS for 20 min, cultures were washed with PBS, pH 7.4 and incubated in PBS containing 5\% of the appropriate normal serum and $0.025 \%$ Triton X-100 (blocking solution) for $45 \mathrm{~min}$ at room temperature. Primary antibodies (monoclonal anti-nestin, Millipore, Burlington, MA, USA) MAB533 1:1000; polyclonal anti-MAP2 Millipore AB5622 1:300; polyclonal anti-GFAP, Dako Z0334 1:500) were then applied and incubated overnight at $4{ }^{\circ} \mathrm{C}$. Cells were then washed 3 times with PBS and incubated for $2 \mathrm{~h}$ at room temperature in a solution containing $10 \mu \mathrm{g} / \mathrm{mL}$ Hoechst 33342 and the appropriate secondary antibodies, FITC- or Cy3-conjugated (Jackson Immuno-Research, West Grove, PA, USA) at a dilution of 1:300. After rinsing with PBS, cells were coverslipped with a DAKO mounting medium (Dako, Carpinteria, CA, USA). Immunostaining specificity was assessed by omitting primary antibodies. For each experiment, 9 random fields for each coverslip were examined and 3 or more independent experiments were analyzed. Immunofluorescence was observed using a Nikon Eclipse TE300 microscope. Nine random fields from each coverslip were photographed with a Nikon DS-U3 digital camera and counted. Nuclear DNA was counterstained with Hoechst 33342. At least 400 cells per experiment were counted and each experiment was repeated from 3 or more separate cultures. Results are expressed as mean \pm SEM.

\subsection{Isolation of $E V S$}

Extracellular vesicles were isolated from the NSPC culture medium by sequential ultracentrifugation. Cells were plated at $6000 \mathrm{cells} / \mathrm{cm}^{2}$ in $3 \mathrm{~T} 75$-coated flasks in expansion medium and $24 \mathrm{~h}$ later the medium was replaced with an EV-harvesting medium (basal medium supplemented with $1 \%$ Invitrogen supplement (ITS), 5\% EV-depleted FBS or $20 \mathrm{ng} / \mathrm{mL}$ BMP4). Then, $15 \mathrm{~mL}$ of EV-harvesting medium was added to flasks every $36 \mathrm{~h}$, collecting a final volume of $45 \mathrm{~mL}$ after 3 days of NSPC differentiation. The medium was subjected to sequential centrifugation and ultracentrifugation (20,000 $\mathrm{g}$ for $20 \mathrm{~min}, 10,000 \mathrm{~g}$ for $30 \mathrm{~min}$ and $100,000 \mathrm{~g}$ for $4 \mathrm{~h}$ at $4{ }^{\circ} \mathrm{C}$ by using a Sorvall SW40 centrifuge 
(Thermo Fisher). The obtained EV pellet was resuspended in 1:700 of its initial volume [32] in phosphate buffered saline (PBS) or sample buffer (without beta-mercaptoethanol). Protein concentration was determined by Lowry assay and equal amounts of protein samples were subjected to SDS-PAGE, followed by immunoblotting.

\subsection{Western Blot Characterization of EVs}

To obtain whole-cell extracts, NSPCs were harvested in a RIPA buffer (320 mM sucrose, $50 \mathrm{mM}$ TRIS $\mathrm{pH} 7.5,1 \%$ Triton X-100, 10\% glycerol) and 1\% of inhibitor of proteases cocktail (Sigma-Aldrich), incubated on ice for $30 \mathrm{~min}$ and centrifuged for $12 \mathrm{~min}$ at 13,000 g. Protein amount was quantified by Bradford assay (BioRad, Hercules, CA, USA) and 10-20 $\mu \mathrm{g}$ of protein was subjected to SDS-polyacrylamide gel electrophoresis and transferred overnight onto a polyvinylidene difluoride membrane (Immobilon-PSQ, Millipore). Membranes were blocked in 5\% nonfat dry milk and then incubated with the following primary antibodies: rabbit anti-HSP90 (1:300, Santa Cruz Biotechnology, Dallas, TX, USA), mouse anti-TSG101 (1:200, Santa Cruz Biotechnology, Dallas, TX, USA), goat anti-CD63 (1:1000, BD Biosciences, San Jose, CA, USA), mouse anti-CD81 (1:500, BD Biosciences, San Jose, CA, USA). Blots were washed, incubated with the appropriate horseradish peroxidase-conjugated secondary antibodies (1:10,000, Jackson Immunoresearch, West Grove, PA, USA), then washed again and finally incubated in lumilight-enhanced chemiluminescence substrate (BioRad) and exposed to Chemidoc (BioRad). Densitometric analysis on scanned blots was performed using the ImageLab program (BioRad).

\subsection{Statistical Analysis}

Comparisons were performed using Student's $t$-test or ANOVA test with multiple comparison. Data are the average of 3 or more independent experiments and are presented as mean \pm SEM. Differences are considered significant at $p<0.05$.

Author Contributions: Conceptualization, E.S., S.B. and G.P.; data curation, E.S., R.C., S.C. and E.C.; formal analysis, S.B. and G.P.; funding acquisition, S.B.; investigation, E.S., R.C., S.C. and E.C.; methodology, E.S., R.C., S.C. and G.P.; resources, S.B.; supervision, E.C., S.B. and G.P.; validation, E.S., R.C. and S.C.; writing-original draft, E.S. and G.P.; writing-review and editing, E.C., S.B. and G.P.

Funding: The authors gratefully acknowledge funding from Progetti Ateneo Sapienza (2016 and 2017) to Stefano Biagioni and Avvio alla Ricerca funds 2018 to Dr. Silvia Cardarelli.

Conflicts of Interest: The authors declare no conflict of interest.

\section{Abbreviations}

$\begin{array}{ll}\text { NSPCs } & \text { Neural Stem Progenitor Cells } \\ \text { EGF } & \text { Epidermal Growth Factor } \\ \text { bFGF } & \text { basic Fibroblast Growth Factor } \\ \text { BMP4 } & \text { Bone Morphogenetic Protein } 4 \\ \text { GFAP } & \text { Glial Fibrillary Acidic Protein } \\ \text { MAP2 } & \text { Microtubule Associated Protein } \\ \text { DMEM } & \text { Dulbecco's Modified Eagle's Medium }\end{array}$

\section{References}

1. Edlund, T.; Jessell, T.M. Progression from extrinsic to intrinsic signaling in cell fate specification: A view from the nervous system. Cell 1999, 96, 211-224. [CrossRef]

2. Ruiz i Altaba, A. Planar and vertical signals in the induction and patterning of the Xenopus nervous system. Development 1992, 116, 67-80. [PubMed]

3. Bertrand, N.; Castro, D.S.; Guillemot, F. Proneural genes and the specification of neural cell types. Nat. Rev. Neurosci. 2002, 3, 517-530. [CrossRef] [PubMed] 
4. Kim, E.J.; Battiste, J.; Nakagawa, Y.; Johnson, J.E. Ascl1 (Mash1) lineage cells contribute to discrete cell populations in CNS architecture. Mol. Cell. Neurosci. 2008, 38, 595-606. [CrossRef] [PubMed]

5. Petryniak, M.A.; Potter, G.B.; Rowitch, D.H.; Rubenstein, J.L. Dlx1 and Dlx2 control neuronal versus oligodendroglial cell fate acquisition in the developing forebrain. Neuron 2007, 55, 417-433. [CrossRef]

6. Conti, L.; Pollard, S.M.; Gorba, T.; Reitano, E.; Toselli, M.; Biella, G.; Sun, Y.; Sanzone, S.; Ying, Q.L.; Cattaneo, E.; et al. Niche-independent symmetrical self-renewal of a mammalian tissue stem cell. PLoS Biol. 2005, 3, e283. [CrossRef] [PubMed]

7. Pollard, S.M.; Conti, L.; Sun, Y.; Goffredo, D.; Smith, A. Adherent neural stem (NS) cells from fetal and adult forebrain. Cereb Cortex 2006, 16 (Suppl. 1), i112-i120. [CrossRef]

8. Soldati, C.; Cacci, E.; Biagioni, S.; Carucci, N.; Lupo, G.; Perrone-Capano, C.; Saggio, I.; Augusti-Tocco, G. Restriction of neural precursor ability to respond to Nurr1 by early regional specification. PLoS ONE 2012, 7, e51798. [CrossRef]

9. Braicu, C.; Tomuleasa, C.; Monroig, P.; Cucuianu, A.; Berindan-Neagoe, I.; Calin, G.A. Exosomes as divine messengers: are they the Hermes of modern molecular oncology? Cell Death Differ. 2015, 22, 34-45. [CrossRef]

10. Simons, M.; Raposo, G. Exosomes-vesicular carriers for intercellular communication. Curr. Opin. Cell Biol. 2009, 21, 575-581. [CrossRef] [PubMed]

11. Nawaz, M.; Fatima, F.; Vallabhaneni, K.C.; Penfornis, P.; Valadi, H.; Ekstrom, K.; Kholia, S.; Whitt, J.D.; Fernandes, J.D.; Pochampally, R.; et al. Extracellular Vesicles: Evolving Factors in Stem Cell Biology. Stem Cells Int. 2016, 2016, 1073140. [CrossRef] [PubMed]

12. Janas, A.M.; Sapon, K.; Janas, T.; Stowell, M.H.; Janas, T. Exosomes and other extracellular vesicles in neural cells and neurodegenerative diseases. Biochim. Biophys. Acta 2016, 1858, 1139-1151. [CrossRef] [PubMed]

13. Kramer-Albers, E.M.; Hill, A.F. Extracellular vesicles: interneural shuttles of complex messages. Curr. Opin. Neurobiol. 2016, 39, 101-107. [CrossRef] [PubMed]

14. Rajendran, L.; Bali, J.; Barr, M.M.; Court, F.A.; Kramer-Albers, E.M.; Picou, F.; Raposo, G.; van der Vos, K.E.; van Niel, G.; Wang, J.; et al. Emerging roles of extracellular vesicles in the nervous system. J. Neurosci. 2014, 34, 15482-15489. [CrossRef] [PubMed]

15. Van Niel, G.; D'Angelo, G.; Raposo, G. Shedding light on the cell biology of extracellular vesicles. Nat. Rev. Mol. Cell Biol. 2018, 19, 213-228. [CrossRef] [PubMed]

16. Nair, R.; Santos, L.; Awasthi, S.; von Erlach, T.; Chow, L.W.; Bertazzo, S.; Stevens, M.M. Extracellular vesicles derived from preosteoblasts influence embryonic stem cell differentiation. Stem Cells Dev. 2014, 23, 1625-1635. [CrossRef]

17. Park, S.; Ahn, E.S.; Kim, Y. Neuroblastoma SH-SY5Y cell-derived exosomes stimulate dendrite-like outgrowths and modify the differentiation of A375 melanoma cells. Cell Biol. Int. 2015, 39, 379-387. [CrossRef]

18. Takeda, Y.S.; Xu, Q. Neuronal Differentiation of Human Mesenchymal Stem Cells Using Exosomes Derived from Differentiating Neuronal Cells. PLoS ONE 2015, 10, e0135111. [CrossRef]

19. Lopez-Verrilli, M.A.; Picou, F.; Court, F.A. Schwann cell-derived exosomes enhance axonal regeneration in the peripheral nervous system. Glia 2013, 61, 1795-1806. [CrossRef]

20. Batiz, L.F.; Castro, M.A.; Burgos, P.V.; Velasquez, Z.D.; Munoz, R.I.; Lafourcade, C.A.; Troncoso-Escudero, P.; Wyneken, U. Exosomes as Novel Regulators of Adult Neurogenic Niches. Front. Cell. Neurosci. 2015, 9, 501. [CrossRef]

21. Luarte, A.; Cisternas, P.; Caviedes, A.; Batiz, L.F.; Lafourcade, C.; Wyneken, U.; Henzi, R. Astrocytes at the Hub of the Stress Response: Potential Modulation of Neurogenesis by miRNAs in Astrocyte-Derived Exosomes. Stem Cells Int. 2017, 2017, 1719050. [CrossRef] [PubMed]

22. Vogel, A.; Upadhya, R.; Shetty, A.K. Neural stem cell derived extracellular vesicles: Attributes and prospects for treating neurodegenerative disorders. EBioMedicine 2018, 38, 273-282. [CrossRef] [PubMed]

23. Jeppesen, D.K.; Hvam, M.L.; Primdahl-Bengtson, B.; Boysen, A.T.; Whitehead, B.; Dyrskjot, L.; Orntoft, T.F.; Howard, K.A.; Ostenfeld, M.S. Comparative analysis of discrete exosome fractions obtained by differential centrifugation. J. Extracell Vesicles 2014, 3, 25011. [CrossRef] [PubMed]

24. Moon, B.S.; Yoon, J.Y.; Kim, M.Y.; Lee, S.H.; Choi, T.; Choi, K.Y. Bone morphogenetic protein 4 stimulates neuronal differentiation of neuronal stem cells through the ERK pathway. Exp. Mol. Med. 2009, 41, 116-125. [CrossRef] [PubMed] 
25. Taheri, B.; Soleimani, M.; Aval, S.F.; Memari, F.; Zarghami, N. C6 glioma-derived microvesicles stimulate the proliferative and metastatic gene expression of normal astrocytes. Neurosci. Lett. 2018, 685, 173-178. [CrossRef] [PubMed]

26. Shelke, G.V.; Lasser, C.; Gho, Y.S.; Lotvall, J. Importance of exosome depletion protocols to eliminate functional and RNA-containing extracellular vesicles from fetal bovine serum. J. Extracell Vesicles 2014, 3, 24783. [CrossRef] [PubMed]

27. Fabbri, A.; Cori, S.; Zanetti, C.; Guidotti, M.; Sargiacomo, M.; Loizzo, S.; Fiorentini, C. Cell-to-cell propagation of the bacterial toxin CNF1 via extracellular vesicles: potential impact on the therapeutic use of the toxin. Toxins (Basel) 2015, 7, 4610-4621. [CrossRef] [PubMed]

28. Jovicic, A.; Gitler, A.D. Distinct repertoires of microRNAs present in mouse astrocytes compared to astrocyte-secreted exosomes. PLoS ONE 2017, 12, e0171418. [CrossRef] [PubMed]

29. Cera, A.A.; Cacci, E.; Toselli, C.; Cardarelli, S.; Bernardi, A.; Gioia, R.; Giorgi, M.; Poiana, G.; Biagioni, S. Egr-1 Maintains NSC Proliferation and Its Overexpression Counteracts Cell Cycle Exit Triggered by the Withdrawal of Epidermal Growth Factor. Dev. Neurosci. 2018, 40, 223-233. [CrossRef]

30. Soldati, C.; Caramanica, P.; Burney, M.J.; Toselli, C.; Bithell, A.; Augusti-Tocco, G.; Stanton, L.W.; Biagioni, S.; Buckley, N.J.; Cacci, E. RE1 silencing transcription factor/neuron-restrictive silencing factor regulates expansion of adult mouse subventricular zone-derived neural stem/progenitor cells in vitro. J. Neurosci. Res. 2015, 93, 1203-1214. [CrossRef]

31. Sinno, M.; Biagioni, S.; Ajmone-Cat, M.A.; Pafumi, I.; Caramanica, P.; Medda, V.; Tonti, G.; Minghetti, L.; Mannello, F.; Cacci, E. The matrix metalloproteinase inhibitor marimastat promotes neural progenitor cell differentiation into neurons by gelatinase-independent TIMP-2-dependent mechanisms. Stem Cells Dev. 2013, 22, 345-358. [CrossRef] [PubMed]

32. Royo, F.; Schlangen, K.; Palomo, L.; Gonzalez, E.; Conde-Vancells, J.; Berisa, A.; Aransay, A.M.; Falcon-Perez, J.M. Transcriptome of extracellular vesicles released by hepatocytes. PLoS ONE 2013, 8, e68693. [CrossRef] [PubMed]

(C) 2019 by the authors. Licensee MDPI, Basel, Switzerland. This article is an open access article distributed under the terms and conditions of the Creative Commons Attribution (CC BY) license (http://creativecommons.org/licenses/by/4.0/). 